\title{
Availability of essential medicines and pharmaceutical inventory management practice at health centers of Adama town, Ethiopia
}

\author{
Adane Teshome Kefale ${ }^{1 *}$ (D) and Hafiza Hayredin Shebo ${ }^{2}$
}

\begin{abstract}
Background: Good inventory management practices in the health facilities are one of the critical aspects that influence the availability of essential medicines (EMs). This study aimed to assess EMs availability and inventory management practices at health centers (HCs) of Adama town, Ethiopia.

Method: Institution based cross sectional survey was conducted among six HCs in Adama Town from March 19 to April 12, 2017. Self-administered questionnaire and observational checklists were used to collect quantitative information. Eleven tracer drugs (TDs) that were selected by the Federal ministry of health and included in the TD list of the HCs were used to assess the availability of EMs at the time of the survey; and during the past 12 months. The data were entered and analyzed using SPSS version 21. The accuracy of record keeping was assessed using inventory management assessment tool (IMAT) indicators.

Result: Five HCs had Essential drug list and the procurement was made as per the list. Out of six HCs, four of them procured EMs from both pharmaceutical fund and supply agency (PFSA) of Ethiopia and private suppliers. Stock status of PFSA and transportation were the major challenges during the procurement process. The overall average availability of TDs on the day of the survey was 76.3\%. Average length of stock out days for TDs during the past 12 months from each HC was 40.6 days. Among the TDs assessed at HCs, oral rehydrating salt was stock outed for 144 days while paracetamol was stock outed only for 1.4 days. The discrepancy of TDs between physical count and on bincard for which physical inventory less than the balance on bincard ranges from 0 to 33.3\%.
\end{abstract}

Conclusion: The availability of EMs was low and there was also poor inventory management practice in some of the HCs during the study period.

Keywords: Essential medicines, Tracer drugs, Stock management

\section{Background}

Medicines are vital components of patient care all over the world. World Health Organization (WHO) define essential medicines (EMs) as products that satisfy the priority healthcare needs of the population which should be available in the health facities at all times in adequate amounts with affordable price by the community [1].

\footnotetext{
* Correspondence: adanet2011@gmail.com

${ }^{1}$ Department of Pharmacy, College of Health Sciences, Mizan-Tepi University, Mizan Aman, Ethiopia

Full list of author information is available at the end of the article
}

Ethiopia has a national drug policy aimed to ensure adequate supply of medicines which are required for treatment of diseases affecting the majority of the country's population [2], which gives the primary mandate to the government. To achieve this, the country developed national list of EMs which guides the decision of all health service providers with regard to selecting and availing the most needed medicines at every level of the healthcare system at all times with affordable cost [3].

Inventory management is vital for pharmaceutical supply system which involves the management of routine pharmaceutical ordering process. It helps to maintain a

(c) The Author(s). 2019 Open Access This article is distributed under the terms of the Creative Commons Attribution 4.0 International License (http://creativecommons.org/licenses/by/4.0/), which permits unrestricted use, distribution, and reproduction in any medium, provided you give appropriate credit to the original author(s) and the source, provide a link to the Creative Commons license, and indicate if changes were made. The Creative Commons Public Domain Dedication waiver (http://creativecommons.org/publicdomain/zero/1.0/) applies to the data made available in this article, unless otherwise stated. 
steady supply to patients, hence preventing product stock out, while minimizing the costs of holding inventory [4]. Accurate and updated stock records are crucial for proper inventory management since they are input to calculate future needs. Holding stocks is important to ensure availability of essential items almost all the time. The selection of items to stock should rely on their value to public health and volume of consumption $[4,5]$. Nowadays, inventory management is assisted with computerized Logistics Management Information System (LMIS) that allows easy recording of all medicines transactions and connects all levels of supply chains [6, 7]. Despite the importance of LMIS in improving efficiency of the overall inventory management process $[8,9]$, it is underutilized in developing countries like Ethiopia [10].

Inventory management plays a major role in providing efficient healthcare in relation to three vital aspects of drug supplies used in the health facilities; availability, safety, and affordability. Those are the most important determinants of quality of care and patient satisfaction with services provided in public health facilities [11, 12]. Poor inventory management might lead to overstocking or under stocking of EMs which subsequently results wastage of resource and increased morbidity and mortality due to shortage of life saving drugs [13-17].

Ministry of health of Ethiopia developed standardized inventory management tools expected to be utilized by public health facilities throughout the country whether operated manually or use LMIS. These are bin card, stock card, Internal Facility Request and Resupply form (IFRR), Report and Requisition Form (RRF). The bin card is kept with the product inside the store and up dated in every transactions while stock card is similar to the bin card but is used to track stock based on issuing and receiving orders. The IFRR voucher is used to report internal transfer of items between the facility's pharmaceutical store and dispensing units. The RRF is used to order health commodities from PFSA whereas RRUC is used to track the transfer of supplies back to PFSA. The ministry recommends physical inventory and updating of bin cards and stock cards on regular basis [6].

As per the WHO recommendation, availability of EMs should be $100 \%$, but it is estimated that about one-third of the world population does not have access to medicines, particularly in Africa and Asia $[18,19]$. Availability of generic medicines at public sectors is less than $60 \%$ across WHO regions, especially in Africa region [20].

In Ethiopia, EMs stock out is still a common problem although the degree is variable from facility to facility, ranged from 26 to $91 \%$ [7, 21-28]. In addition, poor inventory management challenges availability of EMs in the country $[7,22,28]$. Thus, it is crucial to assess the scope of problem in availability of EMs and inventory management practice of $\mathrm{HCs}$ in Adama town for interventions.

\section{Methods}

\section{Study area, design and sampling technique}

The study was conducted at HCs in Adama Town, East Shewa of Oromia region, Ethiopia; located $100 \mathrm{~km}$ East of the capital, Addis Ababa. The town has seven functional HCs namely; Geda HC, Dembela HC, Adama HC, Hawas $\mathrm{HC}$, Biftu HC, Anole HC and Boku HC. Institution based cross sectional study was conducted at six $\mathrm{HCs}$ from March 19 to April 12, 2017. The availability of EMs was assessed at the date of survey and the previous 12 months, from March 2016 to March 2017.

The inclusion criteria of the study were presence of functional store and dispensary unit, EMs and health professionals working at the site for at least 6 months, while medical supplies, equipment and reagents were excluded from the study.

Out of seven HCs in Adama town, six were included in this study. Eleven trace drugs (TDs), which are representatives of EMs expected to be found in $\mathrm{HCs}$, were used to assess availability of EMs at the day of survey and during the previous 12 months. The TDs used for this study were Coartem, rifampicin/isoniazid/ethambutol/pyrazinamide fixed dose combination, Medroxy progesterone injection, Pentavalent vaccine, Amoxicillin $500 \mathrm{mg}$ capsule, Oral Rehydrated Salt (ORS), Mebendazole $100 \mathrm{mg}$ tablet, Tetracycline eye ointment $1 \%$, Paracetamol $500 \mathrm{mg}$ tablet, ergometrine injection and Ferrous Salt plus Folic acid.

The outcome variables of the study were availability of EMs and pharmaceutical inventory practice of HCs in the study area. Data were collected on explanatory variables including sociodemographics of health professionals, use of LMIS, source of drug supply, availability of EDL, functionality of DTC, the presence of guideline for selection, forecasting and procurement, lead time required for supply of procured drugs, transportation during procurement process, the use of FEFO/FIFO and type of logistic forms/ records used to manage EMs

\section{Data collection and analysis}

A structured questionnaire adapted from Logistics Indicator Assessment Tool (LIAT) was used to collect data. LIAT is a tool developed by the USAID funded DELIVER which is used to conduct institution-based survey to assess health commodity logistics system performance and commodity availability at health facilities [29]. The questionnaire contains information about availability of EDs, use of LMIS, methods of inventory management and procurement process. Availability of TDs was also assessed using observational checklist to review data from bin cards. Accuracy of record keeping was evaluated by performing physical count of TDs to estimate the discrepancy between the recorded value and the counted value. 
Data was collected by two trained druggists. Data quality was assured by pretesting at Mizan $\mathrm{HC}$ and training of data collectors on objectives of the study and techniques of data collection. The principal investigators continuously supervised the collection and daily check consistency of the collected data.

The collected quantitative data was entered and analyzed using SPSS 21.0 version for windows. The descriptive data was summarized using frequency and average. For each HC, three indicators were assessed to evaluate stock management practices using the Inventory Management Assessment Tool (IMAT) developed by INFORM program at Management Science for Health [30]. The tool is used to assess the effectiveness of record-keeping and stock management practices in a health facility and provides suggestions for improvement. The indicators used are percentage of recorded balances that is less than physical counts, percentage of recorded balances that is greater than physical counts, and average percentage of days the products were out of stock.

\section{Results}

\section{General characteristics of the study setting}

Of the seven HCs in Adama town, six $(n=6)$ HCs were included in this study. One of the $\mathrm{HC}$ was excluded due to lack of enough records to assess inventory management practice of EMs.

The data collected using questionnaire included six HCs responses whereas the data from the checklists includes response of five HCs. The data was collected both from pharmacy professionals at the dispensary unit and from store keepers of each HCs. Out of six HCs, only two HCs have two personnel (one pharmacist and one druggist) at dispensary units, while the others had only one personnel either pharmacist or druggist at dispensary units.

Among six $\mathrm{HCs}$, five had pharmacists whereas one had druggist at dispensary units. The type of health professionals as a store keeper was different for each $\mathrm{HC}$, only two had pharmacists as a store keeper, three had druggist while one $\mathrm{HC}$ store was managed by nurse.

\section{Availability of essential medicines}

Availability of EMs was assessed by interviewing store keepers on most frequently stock out medicines and observation with checklist. On average, $76.4 \%$ of TDs were available at the day of visit in each $\mathrm{HC}$. The result indicate that on average, each $\mathrm{HC}$ was stock outed $41.8 \%$ of TDs during the past 12 months (Table 1). Of the 11 TDs, six were available in all HCs at the day of visit while ergrometrine injection was stock outed at day of visit and in the last 12 months in all HCs. Interview of stoke keepers revealed that ORS, Amoxacillin syrup 125 $\mathrm{mg} / 5 \mathrm{ml}$, TTEO, FEFOL tab and Ergometrine injection were the most frequently stock outed drugs.

Excluding ergometrine injection, the average stock out days of TDs from all five HCs within the past 12 months was 40.6 days. Among five HCs, ORS was stock out for longer period of time (144 days) whereas paracetamol was stock out for shorter duration which was 1.4 days (Fig. 1).

\section{Inventory management practice of the health centers}

The accuracy of record keeping system in the HCs is summarized by three indicators. Accurate stock record balance ranges from 44.4 to $100 \%$ while percentage of stock record balance that were less than physical inventory ranges from 0 to $33.3 \%$, whereas, percentage of stock record balance that were greater than physical inventory ranges from 0 to $44.4 \%$. The physical inventory was greater than the recorded balance only for one $\mathrm{HC}$ (Fig. 2).

All HCs (six) determined their own drug supply using formula based on their annual consumption. Detail of inventory management practice of $\mathrm{HCs}$ is depicted in Table 2.

\section{Discussion}

The study was aimed to evaluate availability of EMs and pharmaceutical inventory management practices among HCs in Adama town. Availability of drugs largely influence quality of healthcare and patient satisfaction. Stock out of EMs enforces patients to use more costier alternatives. Drug availability is affected by efficiency of inventory management.

Table 1 Availability of EMs during day of visit and stock out review over 12 months of TDs $(n=11)$ at five HCs in Adama Town, March, 2017

\begin{tabular}{llll}
\hline Health Centers & Availability at survey period N (\%) & Stock out during survey period N (\%) & Stock out past, 12 months N (\%) \\
\hline Anole & $10(90.9 \%)$ & $1(9.1 \%)$ & $2(18.2 \%)$ \\
Biftu & $7(63.6 \%)$ & $4(36.4 \%)$ & $5(45.5 \%)$ \\
Dembela & $8(72.7 \%)$ & $3(27.3 \%)$ & $3(27.3 \%)$ \\
Gedda & $10(90.9 \%)$ & $1(9.1 \%)$ & $5(45.5 \%)$ \\
Adama & $7(63.6 \%)$ & $4(36.4 \%)$ & $8(72.7 \%)$ \\
Average & $8.4(76.4 \%)$ & $2.6(23.6 \%)$ & $4.6(41.8 \%)$ \\
\hline
\end{tabular}




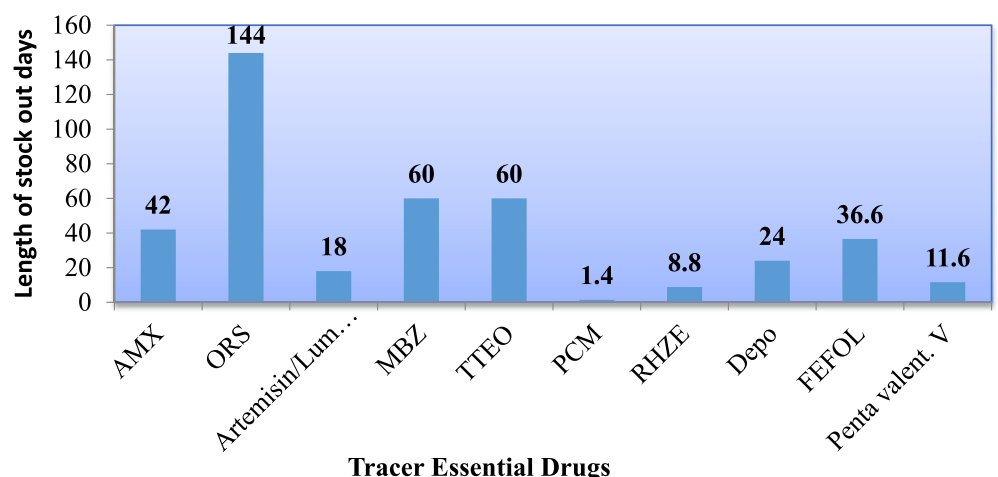

Fig. 1 Average length of stock out days for TDs within the past 12 months at five HCs, Adama town, 2017. (AMX: amoxicillin, MBZ: mebendazole, TTEO: tetracycline eye ointment, PCM: paracetamol, RHZE: Rifampicin, Isoniazid, Pyrazinamide, Ethambutol, Depo: medroxy progesterone, FEFOL: ferrous salt plus folic acid, Pentanta valent. V: pentavalent DPT-HEP-Hib Vaccine)

The overall availability of EMs in this study was far from WHO recommended target point [12]. In 2009, the general availability of EMs in Ethiopia was reported to be $91 \%$ but, study conducted at different part of Ethiopia after 2009 showed big variation on the availability of EMs ranged from 26 to $91 \%$ [22, 27]. The availability of TDs documented in this study is better than Jimma and Amhara region but, lower compared to Gondar and Addis Ababa [16-20]. The reason behind might be due to the stock status of regional PFSA and the budget put on primary public health facilities vary from one region to the other in Ethiopia. When the result of this study compared to Tanzania, it is lower but much higher compared with Ugandan study [15, 31]. Stock outing of EMs at the day of survery in this study $(23.6 \%)$ is higher than previous studies in Tanzania (20\%) [15] and Gondar, Ethiopia (9\%) [22].

The severity of stock out duration of TDs in each HC was assessed by calculating the average stock out days of TDs within the past 12 months. The 1 year average stock out days of TDs in this study is lower when compared to the situation in Uganda, 72.9 days, and higher when compared to the result in Gondar, 30.5 days, [22, 31]. The reason for high stock out period in this study might be due to transportation during procurement process and unavailability of the TDs at PFSA as most professionals stated. Of the 11 TDs, ORS was stocked out for longer period when compared to the other TDs whereas, in Gondar from 26 TDs chloroquine syrup was stocked out for more days [22]. The long stock out period for ORS might be due its' high consumption since it is important lifesaving medicine for diarrheal diseases, common in developing countries like Ethiopia. In addition procurement of drug for HCs is highly bureaucratic. The government allow purchase of drugs from private supplies only when unavailable in PFSA. It also limit quantity of drug to be purchased. High consumption, in the absence of fluidy supply system cause frequent stock out and cumulative longer day of stock out.

The physical count that is less than the balance on bin card is one of the indicators for poor record keeping practice. In this study, the percentage of discrepancy varies among all HCs, highest in Dembela HC. From the store keeper's response, although there is guideline to use LMIS in this $\mathrm{HC}$, the absence of computer software system and lack of training on logistic forms result poor record keeping practice in this HC. The discrepancy was high when compared to one of the public hospitals in Tanzania and lower than one of the HC in Gondar town [13, 22]. Ideally, a facility should not have discrepancies between the physical inventories and the balance on bin

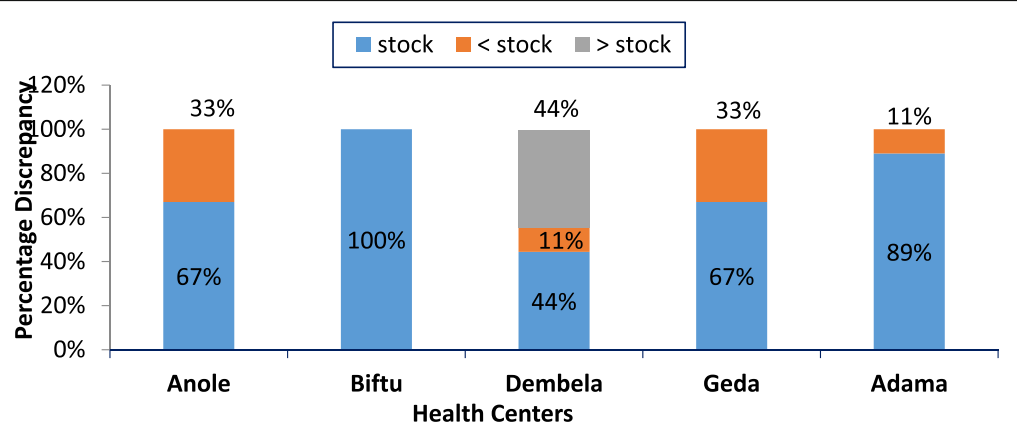

Fig. 2 Percentage discrepancy between physical count and balance on bin card of TDs at five HCs of Adama Town, 2017 
Table 2 Inventory management practices of HCs, Adama Town, 2017. ( $n=6)$

\begin{tabular}{|c|c|c|c|c|c|c|c|}
\hline \multicolumn{2}{|l|}{ Variables } & \multirow{2}{*}{$\begin{array}{l}\text { Adama HC } \\
\text { Yes (Yes) }\end{array}$} & \multirow{2}{*}{$\frac{\text { Anole HC }}{\text { Yes (Yes) }}$} & \multirow{2}{*}{$\frac{\text { Biftu HC }}{\text { Yes (Yes) }}$} & \multirow{2}{*}{$\begin{array}{l}\text { Dembela HC } \\
\text { Yes (No) }\end{array}$} & \multirow{2}{*}{$\frac{\text { Geda HC }}{\text { Yes (Yes) }}$} & \multirow{2}{*}{$\begin{array}{l}\text { Hawas HC } \\
\text { NA }\end{array}$} \\
\hline Bin card available & Amoxicillin & & & & & & \\
\hline & ORS & Yes (Yes) & Yes (Yes) & Yes (Yes) & Yes (Yes) & Yes (Yes) & NA \\
\hline & Mebendazole & Yes (Yes) & Yes (Yes) & Yes (Yes) & Yes (No) & Yes (No) & NA \\
\hline & TTEO & Yes (Yes) & Yes (Yes) & Yes (Yes) & Yes (Yes) & Yes (Yes) & NA \\
\hline & Paracetamol & Yes (Yes) & Yes (Yes) & Yes (Yes) & Yes (No) & Yes (Yes) & NA \\
\hline & FEFOL & Yes (Yes) & Yes (Yes) & Yes (Yes) & Yes (No) & Yes (No) & NA \\
\hline & RHZE & Yes (Yes) & Yes (Yes) & Yes (Yes) & Yes (No) & Yes (Yes) & NA \\
\hline & Depo provera & Yes (Yes) & Yes (Yes) & Yes (Yes) & Yes (Yes) & Yes (Yes) & NA \\
\hline & Ergometrine & No (No) & No (No) & No (No) & No (No) & No (No) & NA \\
\hline & Coartem & Yes (Yes) & Yes (Yes) & Yes (Yes) & Yes (Yes) & $\mathrm{No}(\mathrm{No})$ & NA \\
\hline & Pentavalent V & $\mathrm{No}(\mathrm{No})$ & $\mathrm{No}(\mathrm{No})$ & No (No) & $\mathrm{No}(\mathrm{No})$ & $\mathrm{No}(\mathrm{No})$ & NA \\
\hline \multicolumn{2}{|l|}{ Annual physical inventory } & Yes & No & Yes & No & No & No \\
\hline \multicolumn{2}{|c|}{ Policy and guideline for LMIS } & Yes & Yes & No & Yes & Yes & No \\
\hline \multicolumn{2}{|c|}{ Functional computer system } & Yes & No & No & No & Yes & No \\
\hline \multirow[t]{5}{*}{ Logistic forms used } & Bin cards & Yes & Yes & Yes & Yes & Yes & No \\
\hline & Stock cards & No & Yes & No & Yes & No & No \\
\hline & RRF & Yes & Yes & Yes & Yes & Yes & Yes \\
\hline & IFRR & Yes & No & Yes & Yes & Yes & No \\
\hline & Facility form & Yes & No & No & No & No & No \\
\hline \multicolumn{2}{|c|}{ FEFO/FIFO drug distribution system in the facility } & Yes & Yes & Yes & Yes & Yes & No (random) \\
\hline \multicolumn{2}{|l|}{ Own EDL available } & Yes & Yes & Yes & No & Yes & Yes \\
\hline \multicolumn{2}{|l|}{ Functional DTC available } & Yes & No & Yes & Yes & Yes & No \\
\hline \multicolumn{2}{|c|}{ Who select drugs for EDL inclusion } & DTC & $\begin{array}{l}\text { Pharmacy unit } \\
\text { only }\end{array}$ & DTC & DTC & $\begin{array}{l}\text { By } \mathrm{HC} \\
\text { head }\end{array}$ & $\begin{array}{l}\text { Pharmacy unit } \\
\text { only }\end{array}$ \\
\hline \multirow[t]{2}{*}{ Source of drug } & PFSA & Yes & Yes & Yes & Yes & Yes & Yes \\
\hline & Private supplier & Yes & No & Yes & No & Yes & Yes \\
\hline \multirow[t]{2}{*}{ Transportation of drugs } & From PFSA & The HC & Health bureau & $\begin{array}{l}\text { Health } \\
\text { bureau }\end{array}$ & $\begin{array}{l}\text { Health } \\
\text { bureau }\end{array}$ & The HC & PFSA \\
\hline & $\begin{array}{l}\text { From private } \\
\text { suppliers }\end{array}$ & The HC & NA & $\begin{array}{l}\text { Health } \\
\text { bureau }\end{array}$ & NA & The HC & Heath bureau \\
\hline \multirow[t]{2}{*}{ Lead time } & From PFSA & $\begin{array}{l}\text { Less } 1 \\
\text { week }\end{array}$ & 1 to 2 month & Less 1 week & Less 1 week & $\begin{array}{l}\text { Less } 1 \\
\text { week }\end{array}$ & 2 months \\
\hline & From privates & $\begin{array}{l}\text { Less } 1 \\
\text { week }\end{array}$ & NA & Less 1 week & NA & $\begin{array}{l}\text { Less } 1 \\
\text { week }\end{array}$ & $\begin{array}{l}2 \text { weeks to } 1 \\
\text { month }\end{array}$ \\
\hline
\end{tabular}

card for each item but, in practice there is acceptable level of errors. In general, discrepancies of more than $10 \%$ may require efforts to improve data quality [29]. Thus, except one $\mathrm{HC}$ all the other needs to improve their record keeping practice.

Utilization of different logistic forms is variable among HCs of this study. Bin cards were used in majority of $\mathrm{HCs}$ and updated on transaction which better than reported from Uganda primary health facilities [32]. Effective inventory management should be supported by LMIS. But in this study only two $\mathrm{HCs}$ in Adama town used LMIS in their facility which was low compared to the study done at HCs in Addis Ababa [7]. This might be due to lack of software system to manage their store and lack of training on LMIS in most HCs in Adama town.

Regarding lead time, this study revealed that the lead time was as long as 2 months when EMs procured from PFSA. It is longer when compared to the lead time reported from Addis Ababa, which was 1 week to 2 weeks [7]. This might be due to the stock status of regional PFSA varies from region to region.

This study is limited to one geographical area and single facility level (health centers) only due to 
financial constraints. Extrapolation should be taken with precaution with reviewing similar studies in other settings to get full picture of the country.

\section{Conclusion}

The availability of EMs and the accuracy of record keeping in the HCs were low. The major problem common for all $\mathrm{HCs}$ in the procurement process were PFSA stock status and transportation. The absence of computer software system and lack of enough pharmacy professionals are some of the challenges to perform inventory management practice in the HCs properly, which further decrease the availability of EMs in the facility. We recommend health proffessionals working at respective health centers to improve inventory management practice. The regional health bureau should provide capacity building to $\mathrm{HCs}$ with provision of computers and trainings.

\section{Abbreviations \\ DTC: Drug and Therapeutic committee; EDL: Essential drug list; EMs: Essential medicines; FEFO: First expire first out; FIFO: First in first out; HCs: Health centers; IFRR: Internal facility request and resupply form; IMAT: Inventory management assessment tool; LMIS: Logistic management information system; PFSA: Pharmaceutical fund and supply agency; RRF: Report and requisition form; RRUC: Record for returning unusable commodities; TDs: Tracer drugs; WHO: World Health Organization}

\section{Acknowledgments}

We would like to express our gratitude to health professionals working in HCs for their unreserved cooperation during data acquisition.

\section{Funding}

None.

\section{Availability of data and materials}

The datasets used and analysed during the current study available from the corresponding author on reasonable request.

\section{Authors' contributions}

HHS conceive the study design, lead data acquisition and involved in data analysis and interpretation. ATK conceived study design, involved in data analysis and interpretation, drafted the manuscript. Both authors approved the manuscript for submission.

\section{Ethics approval and consent to participate}

Approval for this study was secured from regional health bureau of Oromia (Ref. No. WEFBMA/1603/09) after bringing letter of cooperation from Mizan Tepi University, Department of Pharmacy (Ref. No. Phar/84/09). Written consent was secured from all participants and no personal identifiers used during data collection. Data was kept confidential by principal investigators.

\section{Consent for publication}

Not applicable.

\section{Competing interests}

The authors declare that they have no competing interests.

\section{Publisher's Note}

Springer Nature remains neutral with regard to jurisdictional claims in published maps and institutional affiliations.

\section{Author details}

'Department of Pharmacy, College of Health Sciences, Mizan-Tepi University, Mizan Aman, Ethiopia. ${ }^{2}$ College of Health and Medical Sciences, School of Pharmacy, Haramaya University, Harar, Ethiopia.
Received: 11 August 2017 Accepted: 9 April 2019

Published online: 25 April 2019

\section{References}

1. World Health organization. The world health report: reducing risks, promotin healthy life. Geneva; 2002. Available from http://www.who.int/ whr/2002/en/whr02 en.pdf. Accessed 11 Aug 2017

2. Federal democratic republic of Ethiopia. National drug policy of the transitional government of Ethiopia. Addis Ababa; 1993. http://apps.who.int/ medicinedocs/documents/s22351en/s22351en.pdf.

3. Food, Medicine and Health care administration and control authority of Ethiopia. National essential medicine list. 5th ed. Addis Ababa; 2014. http:// apps.who.int/medicinedocs/documents/s17823en/s17823en.pdf.

4. Management Science for Health. MDS-3: managing access to medicines and health technologies. Arlington: MSH; 2012. Available from https://www. msh.org/sites/msh.org/files/mds3-jan2014.pdf. Accessed 11 Aug 2017

5. Management Science for Health. Rapid pharmaceutical management assessment: an indicator-based approach. Arlington: MSH; 1995. Available from https://www.msh.org/sites/msh.org/files/rapid-pharmaceuticalmanagement-assessment-indicator-based-approach.pdf. Accessed 11 Aug 2017

6. Federal democratic republic of Ethiopia ministry of Health. Ethiopian hospital reform implementation guideline. Addis Ababa: FMOH; 2010.

7. Mudzteba M. Assessment of pharmaceutical logistics system in health centers of Addis Ababa, Ethiopia: Addis Ababa University; 2014. Available from http://etd.aau.edu.et/handle/123456789/1862. Accessed 11 Aug 2017

8. USAID/DELIVER PROJECT. The logistics handbook: a practical guide for the supply chain management of health commodities. 2011. Available from http://apps.who.int/medicinedocs/documents/s20211en/s20211en.pdf. Accessed 11 Aug 2017

9. USAID| DELIVER PROJECT, Task Order 1. The Logistics Handbook: A Practical Guide for Supply Chain Managers in Family Planning and Health Programs. Arlington: USAID | DELIVER PROJECT; 2007.

10. Shewarega A, Dowling P, Necho W, Tewfik S, Yiegezu Y. Ethiopia: national survey of the integrated pharmaceutical logistics system. Arlington: USAID/ DELIVER PROJECT, Task Order 4, and Pharmaceuticals Fund and Supply Agency (PFSA); 2015.

11. Narkotey AM. Inventory management in the Ghana health service and its role in healthcare delivery: a case study of health facilities in ho municipality, MBA thesis. Kwame Nkrumah University of Science and Technology; 2012. http://ir.knust.edu.gh/bitstream/123456789/4823/1/ Annor\%20Michael\%20Narkotey.pdf.

12. Aronovich GD, Kinzett S. Kenya: assessment of the health commodity supply chains and the role of KEMSA. Arlington; Va:DELIVER/John snow, Inc. for the U.S. Agency for International development (USAID); 2001. Accessed online from https://www.who.int/hiv/amds/countries/ken AssessHealthcommodSup.pdf.

13. Kagashe GAB, Massawe T. Medicine stockout and inventory management problems in public hospitals in Tanzania: A case of Dar Es Salaam region hospitals. Int J Pharm. 2012:2(2):252-9.

14. Whitney BE. Indicators of pharmaceutical supply chain assessment in low and middle-income countries: a systematic review of the literature: Emory University; 2010. https://etd.library.emory.edu/concern/etds/ $7 \mathrm{~d} 278 \mathrm{t} 56 \mathrm{f}$ ?locale $=$ zh

15. Ministry of health and Social Welfare of Tanzania. In-depth assessment of the medicines supply system in Tanzania. Dar es salaam; 2008. http://apps. who.int/medicinedocs/documents/s16503e/s16503e.pdf.

16. Tumwine $Y$, Kutyabami $P$, Odoi RA, Kalyango N. Availability and expiry of essential medicines and supplies during the " pull " and " push " drug acquisition systems in a rural Ugandan hospital. Trop J Pharm Res. 2010; 9(December):557-64.

17. Ventola CL. The drug shortage crisis in the United States causes, impact, and management strategies. P T. 2011;36(11):741-57.

18. World Health organization. WHO policy perspectives on mediciines: equitable access to essential medicines: a framework for collective action. Geneva; 2004. Available from http://apps.who.int/medicinedocs/pdf/s4962e/ s4962e.pdf. Accessed 11 Aug 2017

19. World Health organization. How to investigate drug use in health facilities: selected drug use indicators. Geneva; 1993. Available from http://apps.who. int/medicinedocs/pdf/s2289e/s2289e.pdf. Accessed 11 Aug 2017 
20. Cameron A, Ewen M, Auton M. The world medicines situation 2011 medicines prices, availablity and affordabilty. Geneva; 2011. Available from http://www.who.int/medicines/areas/policy/world_medicines_situation/ WMS ch6 wPricing_v6.pdf. Acceesed on 11 Aug 2017

21. Nigussie WD. Assessment of the degree of adherence to health facility indicators related to rational drug use in selected health facilities of Amhara region, Northwest Ethiopia. Int J Pharma Sci Res. 2014;5(04):171-8.

22. Fentie M, Fenta A, Moges F, Oumer H, Belay S, Sebhat Y. Availability of essential medicines and inventory management practice in primary public health facilities of Gondar town, north West Ethiopia. J PharmaSciTech. 2015:4(2):54-6.

23. Carasso BS, Lagarde M, Tesfaye A, Palmer N. Availability of essential medicines in Ethiopia : an efficiency-equity trade-off ? Trop Med Int Heal. 2009;14(11):1394-400.

24. Abiye Z, Tesfaye A, Hawaze S. Barriers to access : availability and affordability of essential drugs in a retail outlet of a public health center in south western Ethiopia. J Appl Pharm Sci. 2013;3(10):101-5.

25. Sado E, Sufa A. Availability and affordability of essential medicines for children in the Western part of Ethiopia : implication for access. BMC Pediatr. 2016;16(40). https://doi.org/10.1186/s12887-016-0572-3.

26. Ewen M, Kaplan W, Gedif T. Prices and availability of locally produced and imported medicines in Ethiopia report of a survey conducted in August 2013. 2016. Available from http://apps.who.int/medicinedocs/documents/ s23207en/s23207en.pdf. Accessed 21 Nov 2017.

27. Ethiopian Public health Institute. Ethiopia service availability and readiness assessment 2016 summary report. Available from https://www.ephi.gov.et/ images/pictures/download2009/ v6\%20Final\%20SARA\%20Report\%20Jan\%202017.pdf. Accessed 21 Nov 2017.

28. Gurmu TG, Ibrahim AJ. Inventory management performance of key essential medicines in health facilities of east Shewa zone, Oromia regional state, Ethiopia. Cukurovs Med J. 2017:42(2):277-91.

29. USAID/DELIVER PROJECT. Logistics indicators assessment tool (LIAT). 2008. Available from https://pdf.usaid.gov/pdf_docs/Pnade735.pdf. Accessed 11 Aug 2017.

30. Management Science for Health. Inventory management assessment tool (IMAT). Available from https:/www.msh.org/sites/msh.org/files/IMAT-ToolEnglish.xls. Accessed 11 Aug 2017.

31. Uganda Mininstry of Health. Pharmaceutical situation-level-II: health facilies survey in Uganda. 2008.

32. Uganda Ministry of health. Assessment of the essential medicines kit-based supply system in Uganda. 2011

Ready to submit your research? Choose BMC and benefit from:

- fast, convenient online submission

- thorough peer review by experienced researchers in your field

- rapid publication on acceptance

- support for research data, including large and complex data types

- gold Open Access which fosters wider collaboration and increased citations

- maximum visibility for your research: over $100 \mathrm{M}$ website views per year

At $\mathrm{BMC}$, research is always in progress.

Learn more biomedcentral.com/submissions 